\title{
Acetylcholinesterase Immobilized on Magnetic Beads for Pesticides Detection: Application to Olive Oil Analysis
}

\author{
Najwa Ben Oujji ${ }^{1,2}$, Idriss Bakas ${ }^{1,2}$, Georges Istamboulié ${ }^{1}$, Ihya Ait-Ichou ${ }^{2}$, Elhabib Ait-Addi ${ }^{2}$, \\ Régis Rouillon ${ }^{1}$ and Thierry Noguer ${ }^{1, *}$
}

1 IMAGES Laboratory, University of Perpignan, IMAGES EA4218, Building S 52 Av Paul Alduy, 66860 Perpignan Cedex, France; E-Mails: najwa_benoujji@hotmail.com (N.B.O.); idriss_salame@hotmail.com (I.B.); gistamboulie@yahoo.fr (G.I.); rouillon@univ-perp.fr (R.R.)

2 AQUAMAR Laboratory, Photocatalysis and Environment Team, Department of Chemistry, Faculty of Science, University Ibn Zohr, BP 8106 Cité Dakhla, Agadir, Morocco; E-Mails: ihya.aitichou@gmail.com (I.A.-I.); h.aitaddi@esta.ac.ma (E.A.-A.)

* Author to whom correspondence should be addressed; E-Mail: noguer@univ-perp.fr; Tel.: +33-4-68-66-22-55; Fax: +33-4-68-66-22-23.

Received: 4 May 2012; in revised form: 24 May 2012 / Accepted: 4 June 2012 / Published: 8 June 2012

\begin{abstract}
This work presents the development of bioassays and biosensors for the detection of insecticides widely used in the treatment of olive trees. The systems are based on the covalent immobilisation of acetylcholinesterase on magnetic microbeads using either colorimetry or amperometry as detection technique. The magnetic beads were immobilised on screen-printed electrodes or microtitration plates and tested using standard solutions and real samples. The developed devices showed good analytical performances with limits of detection much lower than the maximum residue limit tolerated by international regulations, as well as a good reproducibility and stability.
\end{abstract}

Keywords: electric eel acetylcholinesterase; organophosphorus insecticides; magnetic microbeads; olive oil

\section{Introduction}

Olive cultivation is widespread throughout the Mediterranean region and is important for the rural economy, local heritage and environment [1]. To ensure crop protection, the use of pesticides is often 
required for blocking attacks of pests and diseases, as well as presence of weeds. The olive fruit fly Bactrocera oleae is the most serious pest of olives in the Mediterranean countries, causing economic losses reaching up to $15 \%$ of olive production [2]. Insecticide treatments are applied every year to control the fly population, mainly based on pesticides belonging to the organophosphates class. These chemicals can persist to the harvest stage and are likely to contaminate olive oil. Therefore, both European Union and the Codex Alimentarius Commission of the Food and Agriculture Organization of the United Nations (FAO) have established maximum pesticide residues limits (MRLs) for olives and olive oil $[3,4]$.

Conventional methods of detection of organophosphate pesticides rely on an analysis by gas chromatography with specific detection. Although these techniques are very powerful and can detect very low concentrations, they are still very expensive and require highly skilled personnel, expensive purification steps and specialized major equipment [5]. In the last decades, new technologies based on biological detection systems have emerged. Among these techniques, biosensors have been shown to be very promising due to their simplicity and cost effectiveness compared to conventional techniques. Biosensors based on the inhibition of acetylcholinesterase (AChE) have been intensively studied in the aim of detecting organophosphorus insecticides [6]. Cholinesterases are important enzymes present in vertebrates and insects, which hydrolyze the neurotransmitter acetylcholine in the nervous system [7]. Organophosphorus pesticides are esters, amides or thiol derivatives of phosphoric acid esters. They primarily exist in the thionate form which is stable, but not very active. Activation occurs during metabolic oxidation into the biologically active oxon form, which is much less stable [8]. These insecticides act by phosphorylation of the serine located in the catalytic site of AChE, they can be considered as pseudo-substrates [9]. As this phosphorylation is very difficult to reverse, organophosphates are considered as irreversible inhibitors. This irreversibility is probably the main problem related to AChE-based biosensors, because of the difficulty in performing multiple assays using the same sensor [6]. Several methods have been investigated to overcome this problem, including mainly reactivation using oximes [10] and original immobilisation techniques.

Among these immobilisation methods, magnetic particles have recently gained a great attention due to their potential for providing control of electrochemical processes [11] and creating magneto-switchable devices [12,13]. Immobilization of enzymes, antibodies, oligonucleotides, and other biologically active compounds onto magnetic nanoparticles platforms is a key element in using these structures for biosensing purposes. Fabricating biofunctionalized magnetic materials containing a high amount of the biological element with high activity and stability is essential for the design of robust sensors that take advantage of the magnetic capabilities. The different routes for the fabrication of biofunctionalized magnetic nanoparticles include traditional methods such as covalent binding, adsorption, specific affinity interactions, and entrapment in porous surface layers [14]. Immobilisation of acetylcholinesterase on magnetic microbeads was already described in the literature, based on nickel-histidine affinity $[6,15]$. In this work we propose an immobilisation method that can be applied to the native acetylcholinesterase from electric eel, based on covalent coupling on magnetic microbeads. This method allows designing cheaper biosensors allowing the detection of insecticides in olive oil (Figure 1). The modified beads have been used either in bioassay or in biosensor configurations, based respectively on spectrophotometric or amperometric detection methods. 
Figure 1. Structures of organophosphates and their oxidized forms used in this study: (a) dimethoate and his oxon form omethoate; (b) malathion and malaoxon; (c) methidathion and methidathion oxide.

(a)<smiles>CNC(=O)CSP(=S)(OC)OC</smiles>

(b)<smiles>CCOC(=O)CC(SP(=S)(OC)OC)C(=O)OCC</smiles><smiles>CCOC(=O)CC(SP(=O)(OC)OC)C(=O)OCC</smiles>

(c)<smiles>COc1nn(CSP(=S)(OC)OC)c(=O)s1</smiles><smiles>COc1nn(CSP(=O)(OC)OC)c(=O)s1</smiles>

\section{Experimental Section}

\subsection{Chemicals and Stock Solutions}

AChE (EC 3.1.1.7) from electric eel (EE) (Type V-S, 1,000 U/mg) was purchased from Sigma-Aldrich (St Quentin-Fallavier, France). Acetylthiocholine chloride (ATChCl), acetylthiocholine iodide (ATChI) and 5,5-dithiobis(2-nitrobenzoic acid) (DTNB-Ellman's reagent) were provided by Sigma. In order to minimize hydrolysis, ATChCl and ATChI solutions were prepared daily in $0.9 \% \mathrm{NaCl}$ (Sigma-Aldrich) solution. Stock solutions of enzymes and DTNB were prepared in $0.1 \mathrm{M}$ phosphate buffer $\left(\mathrm{Na}_{2} \mathrm{HPO}_{4} / \mathrm{KH}_{2} \mathrm{PO}_{4}\right.$, Sigma-Aldrich) at $\mathrm{pH}$ 7. The organophosphorus insecticides malaoxon, omethoate and methidathion were purchased from Dr. Ehrenstorfer (Augsburg, Germany). Pesticide stock solutions (concentration $10^{-3} \mathrm{M}$ ) were prepared in acetonitrile (Sigma) and stored at $4{ }^{\circ} \mathrm{C}$, working pesticide solutions were prepared daily in distilled water by dilution of the stock solution. The oxidation of methidathion was achieved using N-bromosuccinimide provided by Sigma-Aldrich. The glutaraldehyde used for activation of magnetic beads was also purchased from Sigma-Aldrich. Carbon (Electrodag 423SS) and silver/silver chloride (Electrodag 418SS) inks were obtained from Acheson (Plymouth, UK). Cobalt phtalocyanine-modified carbon paste was purchased from Gwent Electronic Materials, Ltd. (Gwent, UK). Poly(vinyl)chloride (PVC) sheets $(200 \mathrm{~mm} \times 100 \mathrm{~mm} \times 0.5 \mathrm{~mm})$, supplied by SKK (Denzlingen, Germany), were used as support for the screen-printed electrodes. A glycerophthalic paint (Astral, France) was used as insulating layer. 


\subsection{Apparatus}

Spectrophotometric measurements were performed using a Hewlett Packard diode array 8451A spectrophotometer. Colorimetric measurements on PS-microtiter plates, U form (Greiner, Germany) were performed with a Labsystems Multiskan EX microtiter plate reader (Thermo Life Sciences, France). Amperometric measurements were carried out with a 641VA potentiostat (Metrohm, Switzerland), connected to a BD40 (Kipp \& Zonen, The Netherlands) flatbed recorder.

Screen-printed electrodes were produced using a semi-automatic DEK248 printing machine according to a procedure previously described [15], but in a three-electrode configuration. The working electrode was a $4 \mathrm{~mm}$-diameter disk, the auxiliary electrode was a $16 \mathrm{~mm} \times 1.5 \mathrm{~mm}$ curved line and the $\mathrm{Ag} / \mathrm{AgCl}$ pseudo-reference electrode was a $5 \mathrm{~mm} \times 1.5 \mathrm{~mm}$ straight track. For experiments with magnetic beads, a small $4 \mathrm{~mm}$-diameter magnet was placed on the backside of the working electrode to magnetically attach the enzyme-functionalised beads to the electrode surface.

\subsection{Determination of Acetylcholinesterase Activity}

The activity of AChE was measured spectrophotometrically by monitoring at $412 \mathrm{~nm}$ the appearance of thionitrobenzoate resulting from the reaction of DTNB with thiocholine, the product of the enzymatic hydrolysis of acetylthiocholine substrate, according to the procedure described by Ellman et al. [16]. This method is based on the use of a synthetic substrate: acetylthiocholine, whose hydrolysis liberates thiocholine and acetic acid according to the reaction:

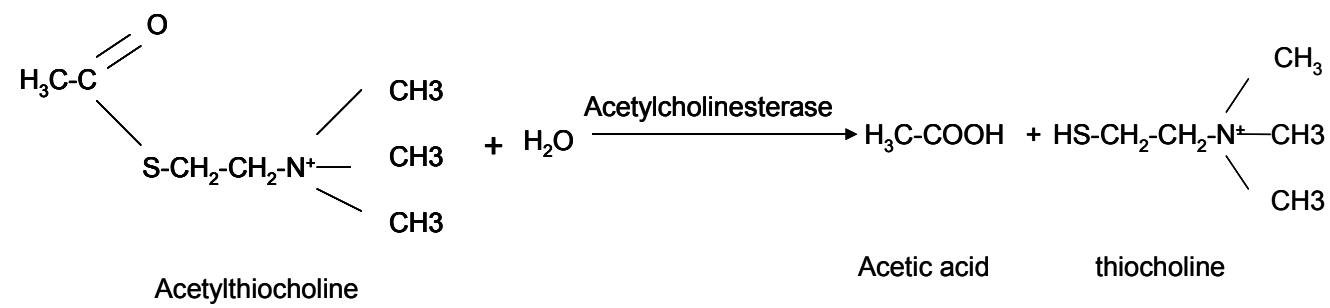

The thiocholine reacts with 5,5'-dithiobis-(2-nitrobenzoic acid) (DTNB) yielding a yellow complex absorbing at $412 \mathrm{~nm}\left(\varepsilon=1.36 \times 10^{4} \mathrm{M}^{-1} \mathrm{~cm}^{-1}\right)$.

\subsection{Determination of the Inhibition Constant ki}

The mechanism of inhibition of AChE by organophosphate compounds is well-known [17]. The inhibitor phosphorylates a serine located in the active site and the inhibition can be considered as irreversible in the first $30 \mathrm{~min}$ [18]:

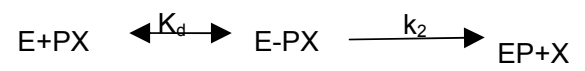

With $\mathrm{E}=$ enzyme, $\mathrm{PX}=$ organophosphate and $\mathrm{X}=$ leaving group. This scheme can be simplified with the bimolecular constant $\mathrm{k}_{\mathrm{i}}=\mathrm{k}_{2} / \mathrm{K}_{\mathrm{d}}$ :

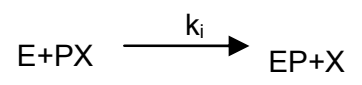


To follow the inhibition, the enzyme was incubated with the pesticide during different periods of time, at $30{ }^{\circ} \mathrm{C}$ in $0.1 \mathrm{M}$ phosphate buffer, $\mathrm{pH}$ 7. The change in remaining free enzyme concentration $[\mathrm{E}] /\left[\mathrm{E}_{0}\right]$ with time was estimated by sampling aliquots at various times and recording the remaining activity in the presence of $1 \mathrm{mM}$ acetylthiocholine [19].

The experimental procedure was as follows: $300 \mu \mathrm{L}$ of $2.5 \times 10^{-3} \mathrm{M}$ DTNB and $100 \mu \mathrm{L}$ of $0.01 \mathrm{M}$ ATChI were added to $500 \mu \mathrm{L}$ of $0.1 \mathrm{M}$ phosphate buffer at $\mathrm{pH} 7$; then $100 \mu \mathrm{L}$ of the enzyme-inhibitor solution were taken at fixed time intervals and added to the cell. The incubation times used to study EE-AChE inhibition were 0, 1, 3, 5, 7, 10, 15 and 20 min.

The residual activity of AChE was calculated by comparing the slope of obtained kinetics before and after inhibition. The graphs obtained by plotting log of residual activity vs. incubation time for each inhibitor showed a linear representation. The apparent reaction rate $\mathrm{k}_{\mathrm{obs}}\left(\mathrm{min}^{-1}\right)$ were obtained by measuring the slope of this straight line. Plotting $1 / \mathrm{k}_{\mathrm{obs}}$ vs. $1 /[\mathrm{I}]$ allowed calculating the inhibition constant $\mathrm{k}_{\mathrm{i}}$, which corresponds to the reciprocal value of the obtained slope.

\subsection{Immobilisation on Magnetic Nanoparticles by Covalent Coupling}

Nickel magnetic beads with a diameter of $200 \mathrm{~nm}$ were activated according to the following steps [20]:

(1) Oxidation of the beads: $60 \mathrm{mg}$ of magnetic beads were stirred for $4 \mathrm{~h}$ in $1 \mathrm{~mL}$ of $0.5 \mathrm{M}$ sulfuric acid, and then washed twice with distilled water.

(2) Functionalization with an amine group: $70 \mu \mathrm{L}$ of 3-aminopropyltriethoxysilane were added to the beads previously poured in $100 \mathrm{~mL}$ of ethanol and ultrasonicated during $5 \mathrm{~min}$, the suspension was kept under mechanical stirring overnight and finally washed three times with ethanol and twice with distilled water.

(3) Covalent coupling with glutaraldehyde: $30 \mu \mathrm{L}$ of aminated beads were washed twice with $1 \mathrm{~mL}$ of $0.1 \mathrm{M} \mathrm{pH} 7$ buffer. $820 \mu \mathrm{L}$ of buffer, $100 \mu \mathrm{L}$ of electric eel AChE $(4.41 \mathrm{UI} / \mathrm{mL})$ and $80 \mu \mathrm{L}$ of a $25 \%$ glutaraldehyde solution were added to the beads and stirred during $30 \mathrm{~min}$ at room temperature.

(4) $1 \mu \mathrm{L}$ of the obtained enzyme-linked beads suspension was placed either on the surface of the working electrode, beforehand fitted with a $4 \mathrm{~mm}$-diameter magnet (amperometric detection), or in each well of the microplate (colorimetric detection).

\subsection{Measurements}

\subsubsection{Amperometric Measurements}

The electrode was vertically immersed in a thermostated cell $\left(30^{\circ} \mathrm{C}\right)$ containing $10 \mathrm{~mL}$ phosphate buffer $\mathrm{pH} 7$ under constant magnetic stirring (417 rpm). The applied potential was $100 \mathrm{mV}$ vs. $\mathrm{Ag} / \mathrm{AgCl}$ reference electrode, using cobalt phtalocyanine as mediator. The current intensity was recorded and, after current stabilisation, $1 \mathrm{mM}$ ATCh (final concentration) was added in the cell. The measured signal corresponded to the difference of current intensity between the baseline and the plateau. The cell was washed with distilled water between measurements.

The pesticide detection was made in a three-step procedure as follows: first, the initial response of the electrode to $1 \mathrm{mM}$ ATCh was recorded three times, then the electrode was incubated in a solution 
containing a known concentration of insecticide, and finally the residual response of the electrode was recorded again. Electrodes were thoroughly washed with distilled water between each measurement. The percentage of the inhibition was correlated with the insecticide concentration, the inhibition rate was calculated according to the following formula: $\mathrm{I}(\%)=\left[\left(\mathrm{I}_{0}-\mathrm{I}\right) / \mathrm{I}_{0}\right] 100, \mathrm{I}$ and $\mathrm{I}_{0}$ being respectively the current after the and before inhibition.

\subsubsection{Colorimetric Measurements}

Two hundred $\mu \mathrm{L}$ of phosphate buffer $\mathrm{pH} 8$ were added in each well containing AChE-modified magnetic beads suspension in order to equilibrate the enzyme. After removal of the liquid using the Adem-Mag96 [21] $200 \mu \mathrm{L}$ of phosphate buffer containing $2 \mathrm{mM} \mathrm{ACTh-I}$ and 6\% DTNB were added and the microplate was incubated for 30 min under constant orbital stirring (300 rpm). The absorbance was then measured at $405 \mathrm{~nm}$ using $100 \mu \mathrm{L}$ of the solution taken from each well. Inhibition experiments were performed by incubating the magnetic beads $(1 \mu \mathrm{L})$ with $100 \mu \mathrm{L}$ of different concentrations of pesticide during $10 \mathrm{~min}$. The measurement procedure was the same as described above.

\subsection{Extraction Procedure}

The determination of the three pesticides in natural oil samples was performed after a simple liquid-liquid extraction procedure. The extraction was performed using $10 \mathrm{~mL}$ of olive oil previously spiked with pesticides at final concentrations of $10^{-2} \mathrm{M}$ for omethoate and methidathion, and $10^{-3} \mathrm{M}$ for malaoxon. The mixture was heated at $50{ }^{\circ} \mathrm{C}$ for $30 \mathrm{~min}$, and $500 \mu \mathrm{L}$ of this olive oil was added to $400 \mu \mathrm{L}$ of acetonitrile and $100 \mu \mathrm{L}$ of dichloromethane. The mixture was centrifuged at 13,400 rpm for $90 \mathrm{~s}$ and the resulting supernatant was recovered and used as a pesticide mother solution, other pesticide solutions were prepared by diluting this mother solution.

\subsection{Oxidation of Methidathion}

In this study we have focused on the detection of oxidized forms of each pesticide, which are less stable but more toxic than the normal forms. The oxidized forms of dimethoate and malathion, respectively called omethoate and malaoxon are commercially available, but in the case of methidathion an oxidation step must be carried out using $N$-bromosuccinimide (NBS). The efficiency of this oxidation step was controlled using reverse-phase HPLC, it was shown that $3 \times 10^{-5} \mathrm{M}$ NBS was sufficient for the total oxidation of a $10^{-5} \mathrm{M}$ methidathion solution. The effect of NBS on AChE was investigated to ensure that the enzyme is not affected by the oxidizing agent, it was shown that in assays conditions NBS did not inhibit AChE.

\section{Results and Discussion}

\subsection{Determination of the Inhibition Constant ki}

The inhibition constants $\mathrm{k}_{\mathrm{i}}$ were calculated by performing enzyme kinetic measurements using different pesticide concentrations and by varying the incubation time of the enzyme with the pesticide. The residual enzyme activity was determined according to the Ellman's spectrophotometric method as 
described previously. The inhibition constant $\mathrm{k}_{\mathrm{i}}$ is proportional to the affinity of the pesticide for the enzyme and its inhibitory power. $\mathrm{k}_{\mathrm{i}}$ is therefore a fundamental parameter to compare the inhibitory potency of insecticides and assess the sensitivity of the enzymes studied. The constants $\mathrm{k}_{\mathrm{i}}$ presented in Table 1 have been determined by studying the residual activity of the enzyme after contact with different concentrations of inhibitor for a given incubation time. This value of $\mathrm{k}_{\mathrm{i}}$ shows that the acetylcholinesterase of electric eel is highly sensitive to malaoxon and methidathion but very weakly sensitive to omethoate.

Table 1. Inhibition constants $\mathrm{ki}\left(\mu \mathrm{M}^{-1} \cdot \mathrm{min}^{-1}\right)$ obtained for methidathion, malaoxon and omethoate.

\begin{tabular}{cccc}
\hline & Methidathion & Malaoxon & Omethoate \\
\hline AChE-EE & 1.07 & 2.98 & 0.001 \\
\hline
\end{tabular}

\subsection{Detection of Insecticides in Microplate Assays}

\subsubsection{Optimisation of the Reaction Time}

The time of reaction of acetylthiocholine with immobilized AChE was studied by measuring every $5 \mathrm{~min}$ the appearance of the yellow complex at $412 \mathrm{~nm}$. It was shown that the reaction was completed after $30 \mathrm{~min}$ in absence of pesticide; this time was therefore used in inhibition measurements.

\subsubsection{Detection of Organophosphates by Colorimetric Method}

The inhibition effect of malaoxon, methidathion and omethoate on Electric eel AChE was studied using an incubation time of $10 \mathrm{~min}$ and a measurement time of $30 \mathrm{~min}$. Figure 2 shows the inhibition rates obtained with each pesticide as a function of the concentration used.

Figure 2. Inhibition effect of omethoate, methidathion and malaoxon on electric eel AChE immobilized on magnetic beads, measurement by colorimetric method.

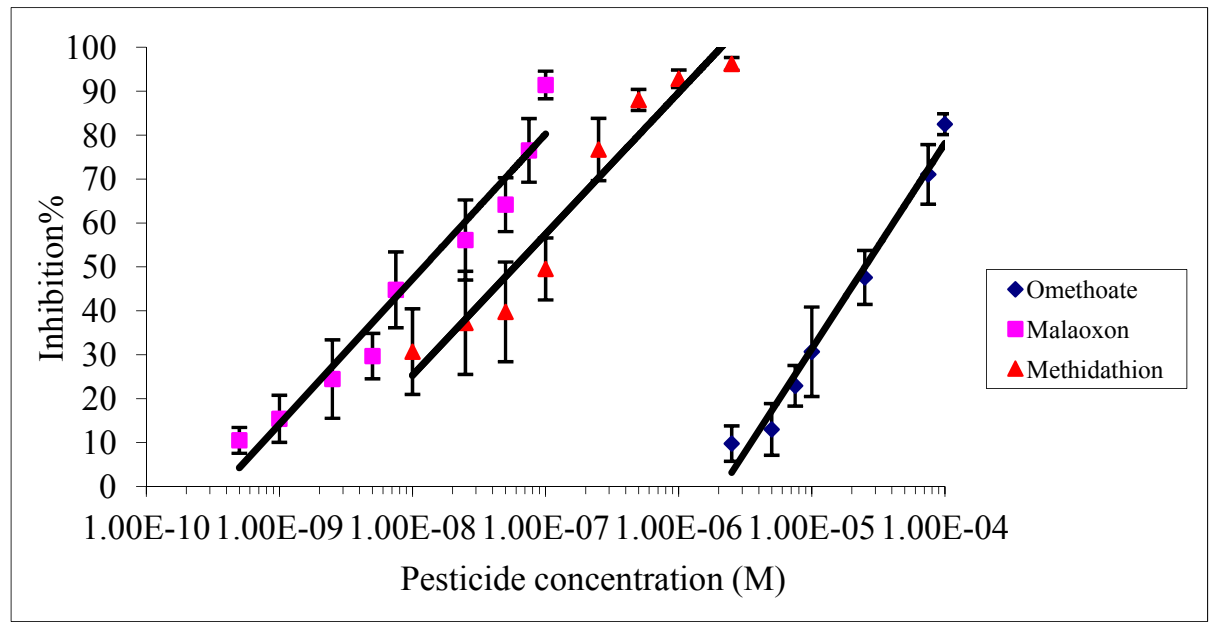

As expected from the values of inhibition constants (Table 1), the inhibitory effect of omethoate was the weaker and malaoxon was the more effective inhibitor. The limit of detection (LOD) and the IC50 were calculated as the pesticide concentration inducing respectively $10 \%$ and $50 \%$ inhibition. The IC10 and IC50 obtained for each pesticide are summarized in Table 2. 
Table 2. The $\mathrm{IC}_{50}$ and $\mathrm{IC}_{10}$ values $(\mathrm{M})$ obtained with the two detection methods with the three pesticides.

\begin{tabular}{ccccc}
\hline & \multicolumn{2}{c}{ Colorimetric detection } & \multicolumn{2}{c}{ Amperometric detection } \\
& \multicolumn{2}{c}{ Pesticide concentration (M) } & \multicolumn{2}{c}{ Pesticide concentration (M) } \\
& $\mathrm{IC}_{10}$ & $\mathrm{IC}_{50}$ & $\mathrm{IC}_{10}$ & $\mathrm{IC}_{50}$ \\
\hline Omethoate & $3.45 \mathrm{E}-06$ & $2.65 \mathrm{E}-05$ & $5.15 \mathrm{E}-06$ & $4.46 \mathrm{E}-05$ \\
Methidathion & $2.50 \mathrm{E}-09$ & $5.80 \mathrm{E}-08$ & $8.85 \mathrm{E}-09$ & $1.36 \mathrm{E}-07$ \\
Malaoxon & $8.00 \mathrm{E}-10$ & $1.30 \mathrm{E}-08$ & $9.40 \mathrm{E}-09$ & $1.00 \mathrm{E}-07$ \\
\hline
\end{tabular}

Beside these results, the microplate assay showed a good reproducibility with a stable response, this detection method has the advantage of saving time as it allows analysing 96 samples in a single assay. Furthermore, due to the small volumes used, it allows one to minimize the use of reagents, however this characteristic can be considered also as a disadvantage because of the difficulty to maintain good reproducibility using small volumes.

\subsection{Detection of Organophosphates by an Amperometric Method}

The operational stability of biosensors based on AChE covalently bound to magnetic beads was tested to ensure that any decrease in the signal was related to enzyme inactivation and not to enzyme leakage. This parameter was estimated by repetitive measurements of the response of a single electrode to $1 \mathrm{mM}$ ATCh, with intermediate rinses with distilled water. In these conditions, the designed sensors showed a very good stability for at least 10 consecutive measurements with a relative standard deviation (R.S.D) in order of 3\% (300 $\pm 10 \mathrm{nA})$. The reproducibility of the inhibition was estimated by measuring six times the inhibition percentage by $3 \times 10^{-8}$ of oxidized methidathion, the R.S.D of the inhibition determination was $4 \%(217 \pm 10)$.

Figure 3. Inhibition effect of omethoate, methidathion and malaoxon on the amperometric biosensor based on electric eel AChE covalently immobilized on magnetic microbeads.

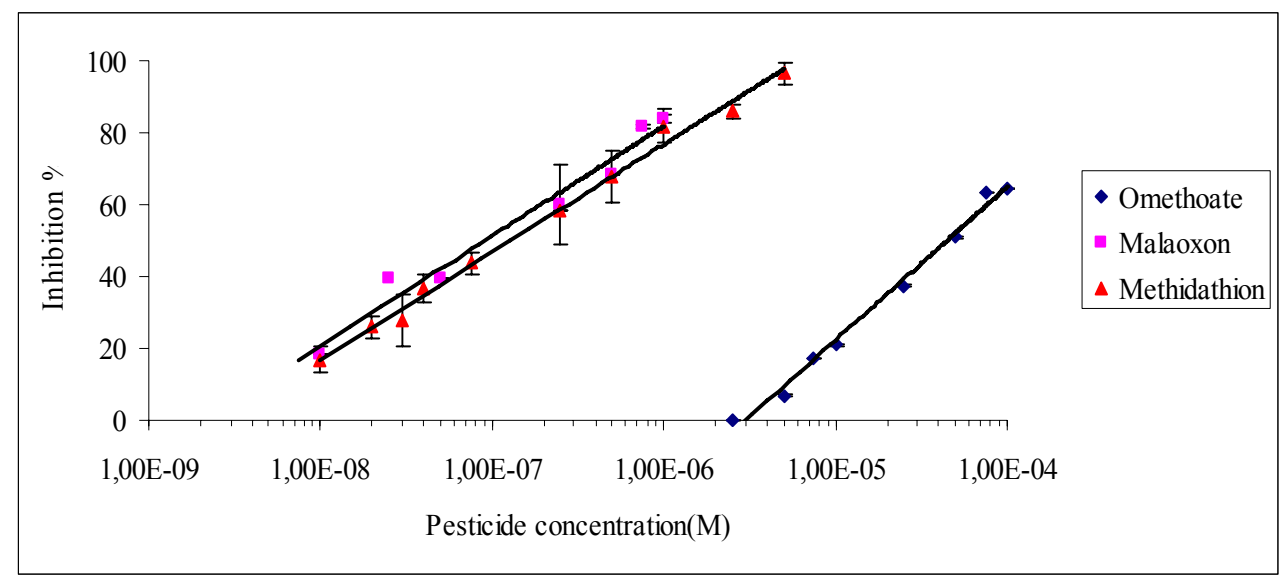

The incubation time between the biosensor and pesticides was also tested. It was observed that an incubation time of 10 min was sufficient to reach the maximum inhibition rate whatever the pesticide concentration used. This incubation time was thus selected and used for all inhibition assays. Figure 3 presents the inhibition effect of the three pesticides on the biosensor. As expected the biosensor 
displays a very low limit of detection for malaoxon and methidathion, while omethoate is detected with a very low sensitivity (Figure 3 ). The $\mathrm{IC}_{10}$ and $\mathrm{IC}_{50}$ values obtained for each pesticide are summarized in Table 2.

\subsection{Application to Real Samples}

The performance of the biosensors was tested using olive oil samples previously spiked with known concentrations of pesticides. In order to measure the efficiency of the extraction procedure, three olive oil samples were spiked to obtain $10^{-2} \mathrm{M}$ of omethoate as final concentration and extracted according to the method described in Section 2.7. The inhibition effect of the resulting extracts was measured after dilution in the working buffer, at a final concentration of $10^{-4} \mathrm{M}$. In these conditions, the average response of the sensors was $75 \pm 7 \mathrm{nA}$, showing a good reproducibility of the extraction method. The recovery percentage for the three pesticides was calculated using the formula below:

\section{Recovery $\%=\%$ of inhibition in real samples $/ \%$ of inhibition in buffer $\times 100$}

It was found that the recovery percentage for the three pesticides with both methods varies from $40 \%$ to $170 \%$, as shown in Figures 4 and 5 . The results showed a very satisfying correlation whatever the format used, i.e., microplate assay (Figure 4) or biosensor (Figure 5).

Figure 4. Comparison of inhibition effects of omethoate, methidathion and malaoxon in olive oil real samples and buffer, detection by optical method.
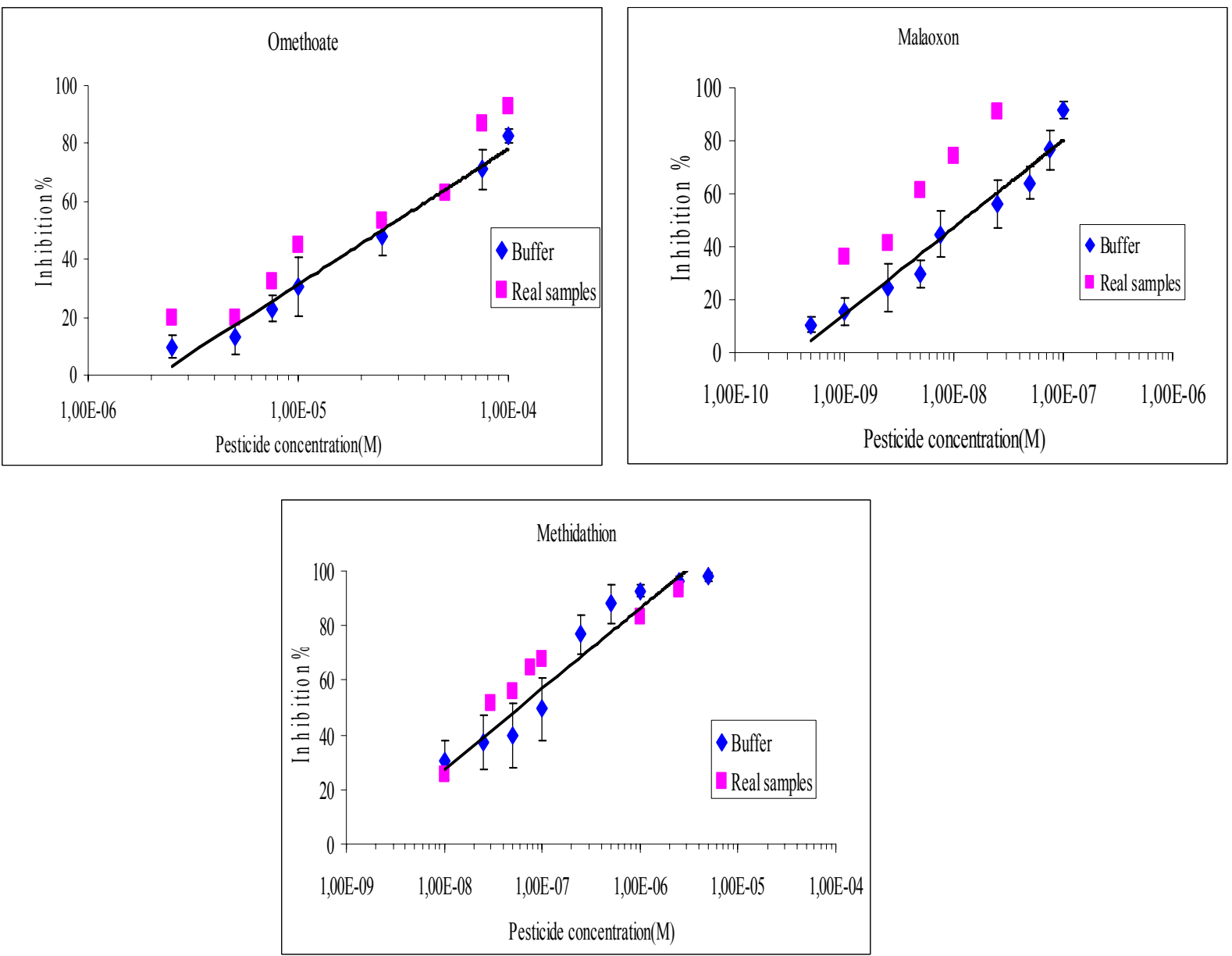
Figure 5. Comparison of inhibition effects of omethoate, methidathion and malaoxon in buffer or olive oil real samples, detection by amperometric method.
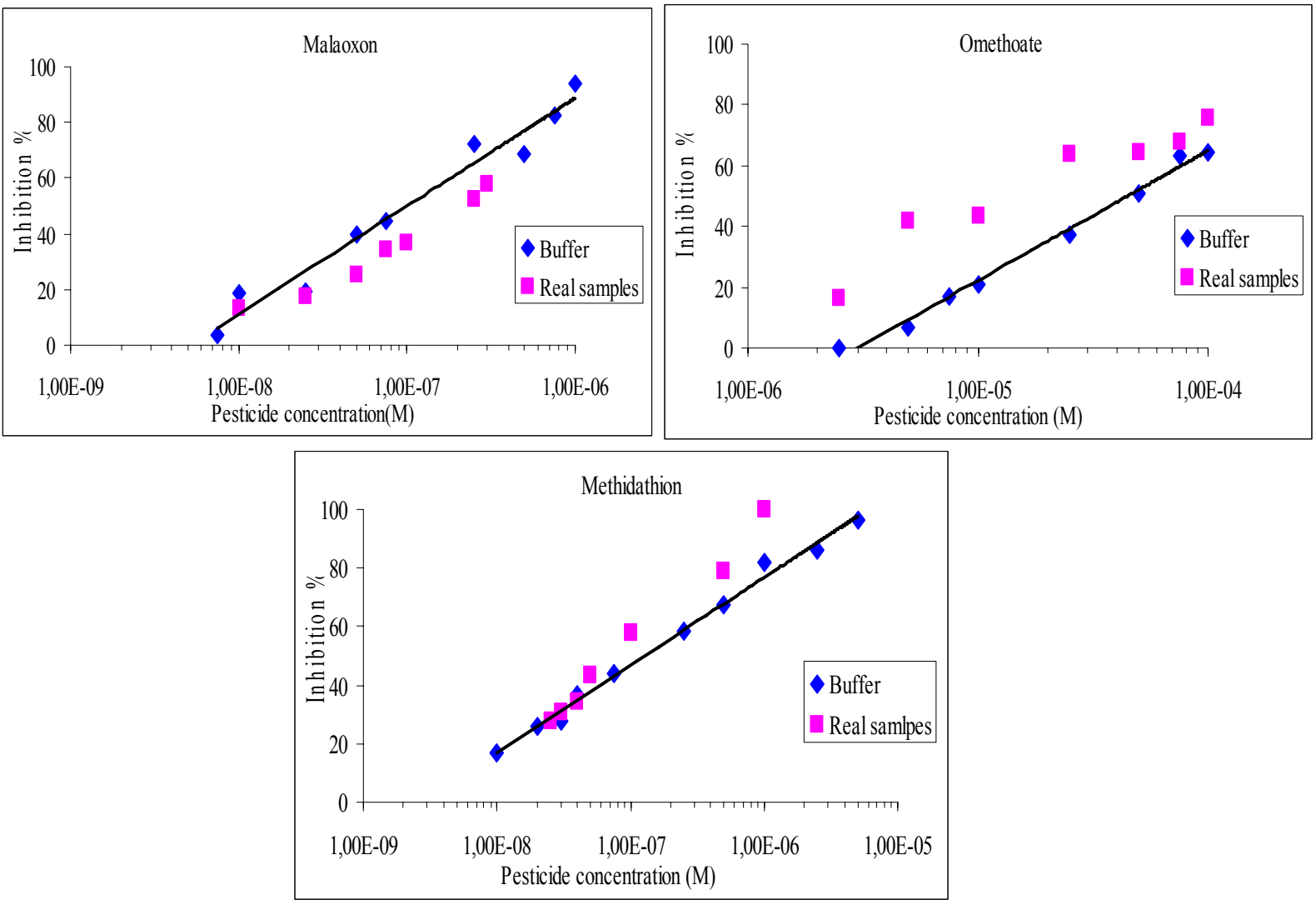

Despite that, a small increase of the inhibition effect was observed whatever the pesticide studied, especially when using the microplate assay. These small discrepancies could be attributed to matrix effects. In order to evaluate these interferences, a blank assay was carried out using an olive oil sample that was previously extracted and then spiked to obtain $10^{-2} \mathrm{M}$ of omethoate. It was found that the matrix effect was responsible of a 5.5\% supplementary loss of the sensor response, which can explain the increase in inhibition ratios observed using real samples. Additional blank assays were performed to verify that the inhibition was not due to pesticides already present in the olive oil, these tests showed very low inhibition rates, lower than $4 \%$. The inhibition effect of olive oil samples containing NBS has also been studied, it was shown that NBS did not affect the measurement.

\section{Conclusions/Outlook}

In this work we have developed and optimised the immobilisation of acetylcholinesterase on magnetic microbeads by covalent coupling. The modified beads have been used in two configurations, using either microplates or screen-printed electrodes supports. Depending on the configuration, colorimetry or amperometry have been applied as detection methods and the devices have been tested on standard and real samples for the determination of three pesticides commonly used for the treatment of olive trees: omethoate, malaoxon and methidathion. The results showed a good performance of the developed devices with reasonable limits of detection, as well as good reproducibility and stability. These last two criteria were however weaker for the colorimetric method due to the difficulty in 
handling small volumes in the microplate assay. On the other hand, this configuration had the advantage of being faster and more economical. This study highlighted the low sensitivity of the electric eel acetylcholinesterase for omethoate compared to malaoxon and oxidized methidathion, which lead to detection limits as low as $10^{-10} \mathrm{M}$. The application on the spiked olive oil samples showed very satisfactory results, comparable with those obtained using standard solutions.

\section{Acknowledgments}

Ben Oujji Najwa would like to express gratitude to the Averroes Programme (EC programme Erasmus Mundus, Action 2) for financially supporting this work.

\section{References}

1. Kandylis, P.; Vekiari, A.S.; Kanellaki, M.; Grati, K.; Msallem, M.; Kourkoutas, Y. Comparative study of extra virgin olive oil flavor profile of Koroneiki variety (Olea europaea var. Microcarpa alba) cultivated in Greece and Tunisia during one period of harvesting. LWT-Food Sci. Technol. 2011, 44, 1333-1341.

2. Mazomenos, B.E.; Pantazi-Mazomenou, A.; Stefanou, D. Attract and kill of the olive fruit fly Bactrocera oleae in Greece as a part of an integrated control system. IOBC - WPRS Bull. 2002, 25, 137-146.

3. Luchetti, F. Importance and future of olive oil in the world market-An introduction to olive oil. Eur. Lipid J. Sci. Technol. 2002, 104, 559-563.

4. Lentza-Rizos, C.; Avramides, E.J. Pesticide residues in olive oil. Rev. Environ. Contam. Toxicol. 1995, 141, 111-134.

5. Istamboulie, G.; Cortina-Puig, M.; Marty, J.-L.; Noguer, T. The use of Artificial Neural Networks for the selective detection of two organophosphate insecticides: Chlorpyrifos and chlorfenvinfos. Talanta 2009, 79, 507-511.

6. Istamboulie, G.; Andreescu, S.; Marty, J.L.; Noguer, T. Highly sensitive detection of organophosphorus insecticides using magnetic microbeads and genetically engineered acetylcholinesterase. Biosens. Bioelectron. 2007, 23, 506-512.

7. Fest, C.; Schmidt, K.-J. Refereneces. In The Chemistry of Organophosphorus Pesticides, Reactivity, Synthesis, Mode of Action, Toxicology; Springer-Verlag Heidelberg: New York, NY, USA, 1973; pp. 122-124.

8. Ballantyne, B.; Marrs, T.C. Overview of the Biological and Clinical Aspects of Organophosphates and Carbamates. In Clinical and Experimental Toxicology of Organophosphates and Carbamates; Ballantyne, B., Marrs, T.C., Eds.; Butterworth-Heinemann Elsevier Ltd.: Oxford, UK, 1992; pp. 3-14.

9. Eldefrawi, A.T. References. In Comprehensive Insect Physiology, Biochemistry and Pharmacology; Kerkut, G.A., Gilbert, L.I., Eds.; Pergamon Press: Oxford, UK, 1985; pp. 115-130.

10. Gulla, K.C.; Gouda, M.D.; Thakur, M.S.; Karanth, N.G. Reactivation of immobilized acetylcholinesterase in an amperometric biosensor for organophosphorus pesticide. Biochim. Biophys. Acta 2002, 1597, 133-139. 
11. Wang, J.; Musameh, M.; Laocharoensuk, R. Magnetic catalytic nickel particles for on-demand control of electrocatalytic processes. Electrochem. Commun. 2005, 7, 652-656.

12. Katz, E.; Willner, I. Magneto-stimulated hydrodynamic control of electrocatalytic and bioelectrocatalytic processes. J. Am. Chem. Soc. 2004, 124, 10290-10291.

13. Katz, E.; Baron, R.; Willner, I. Magnetoswitchable electrochemistry gated by alkylchainfunctionalized magnetic nanoparticles: Controlling of diffusional and surface-confined electrochemical process. J. Am. Chem. Soc. 2005, 127, 4060-4070.

14. Stanciu, L.; Won, Y.-H.; Ganesana, M.; Andreescu, S. Magnetic particle-based hybrid platforms for bioanalytical sensors. Sensors 2009, 9, 2976-2999.

15. Andreescu, S.; Barthelmebs, L.; Marty, J.-L. Immobilisation of AChE on screen-printed electrodes: Comparative study between three immobilisation methods; Applications to the detection of organophosphorus insecticides. Anal. Chim. Acta 2002, 464, 171-180.

16. Ellman, G.L.; Courtney, K.D.; Andres, V.; Featherstone, R.M. A new and rapid colorimetric determination of acetylcholinesterase activity. Biochem. Pharm. 1961, 7, 88-95.

17. Aldridge, W.N. Some properties of specific cholinesterases with particular reference to the mechanism of inhibition by diethyl p-nitrophenyl thiophosphate (E605) and analogues. Biochem. J. 1950, 46, 451-456.

18. Boublik, Y.; Saint-Aguet, P.; Lougarre, A.; Arnaud, M.; Villatte, F.; Estrada-Mondaca S. Acetylcholinesterase engineering for detection of insecticide residues. Protein Eng. 2002, 15, $43-50$.

19. Rhouati, A.; Istamboulie, G.; Cortina-Puig, M.; Marty, J.L.; Noguer, T. Selective spectrophotometric detection of insecticides using cholinesterases, phosphotriesterase and chemometric analysis. Enzyme Microb. Technol. 2010, 46, 212-216.

20. Rossi, L.M.; Quach, A.D.; Rosenzweig, Z. Glucose oxidase-magnetite nanoparticles biconjucate for glucose sensing. Anal. Bioanal. Chem. 2004, 380, 606-613.

21. Barthelmebs, L.; Hayat, A.; Wis, A.; Marty, J.-L.; Noguer, T. Electrochemical DNA aptamer-based biosensor for OTA detection, using superparamagnetic nanoparticles. Sens. Actuators B Chem. 2011, 156, 932-937.

(C) 2012 by the authors; licensee MDPI, Basel, Switzerland. This article is an open access article distributed under the terms and conditions of the Creative Commons Attribution license (http://creativecommons.org/licenses/by/3.0/). 